must be based on pragmatic considerations".

Harris (chapter 12) presents criticisms of two recent committees' reports on biotechnology and genetic engineering, the Clothier Committee and a BMA committee. He argues that many of the summary conclusions of these committees are unexamined personal prejudices that parade as moral principles. For example, why is it acceptable to try and attain certain ends such as increasing academic performance by social engineering but not by genetic engineering? $\mathrm{He}$ claims that the committees failed to examine these distinctions adequately.

Harris argues convincingly that these committees, by strenuously avoiding prescriptive behaviour, have merely followed the uninformed, unreflective prejudice of the common person, and so have misunderstood their task: "Their task, I believe, is to attempt to lead public opinion, not to follow it." He concludes that ". . . the standards of safety should not be rigged so that they effectively rule out germ-line therapy".

I found this book a stimulating and thought-provoking collection of disparate chapters, which seem to me to reflect the arbitrary and personal concerns of individuals in much the same way that scientists develop arbitrary and personal interests in certain aspects of nature. A weakness of the book is the low proportion of authors who are practising scientists. If I were to edit a book on the biology of ethics I should hope to attract several authors to write on ethics as well as biology. Having said that, I must admit that I found by far the clearest and most enjoyable chapters in this volume were written by philosophers.

C R M BANGHAM Department of Immunology, Imperial College School of Medicine, Norfolk Place, London W2 1PG

\section{Ethics in Epidemiology and Clinical Research, Annotated Readings}

Edited by Steven S Coughlin, Newton Mass, Epidemiology Resources Inc, 1995, 272 pages, US $\$ 35.00 \mathrm{pb}$.
These twenty-three articles on the ethics of epidemiological and clinical research have been selected from influential contributions to the subject written between 1963 and 1994. The material has been organised into four sections of varying lengths. The first section consists of three papers which reflect on the often notorious ethical history of epidemiological research: the opening article surveys the state of the art around the time of US Army surgeon, Walter Reed's, humanely conducted yellow fever experiments at the turn of the century. This article is followed by a study of Pasteur's work on rabies. The section is completed with Allan Brandt's article on the Tuskegee Syphilis Study, which reveals how ethically unreflective science can be permeated with highly contestable values. The Tuskegee Syphilis Study began in the 1930s and was designed to determine the natural outcome of untreated latent syphilis in black males. This study, which ran until the 1970s when it was widely condemned in the press, had built-in assumptions of racial inferiority and the crude social Darwinism which had a foothold in US science during the 1930 s. It involved a possible 100 deaths due to the withholding of treatment for experimental reasons.

In the second section five articles examine more general issues in ethics and clinical research on human subjects. The third section consists of six articles which assess ethical issues in randomised control trials. Here the familiar ethical problem is that of balancing potential harms to individual patients with the possible gains to future patients or society as a whole. The remaining nine articles in the final section focus on the evolution of ethics in epidemiology. These articles are indicative of the growing impact of bioethics on the subject. This evolutionary process can be summarised as follows: in the immediate post-war era ethical issues were rarely addressed in epidemiological literature. But in the early 1970 s scandals, such as the Tuskegee Syphilis Study, and the Jewish Chronic Disease Hospital Study (in which live cancer cells were injected into patients who had not given informed consent) fuelled concern over the potential ethical conflicts and dilemmas in epidemiology and clinical research on human subjects. By the mid-1980s discussion of both national and international guidelines was a firmly established aspect of the subject. The articles in the final section provide a comprehensive review of these ethical debates.

This is a well-balanced collection of ethical and historical topics which provides a useful guide to the development of ethical thinking in epidemiological research and the impact of bioethics on the subject.

DAVID LAMB University of Birmingham

\section{Therapy Abatement, Autonomy and Futility: Ethical Decisions at the Edge of Life}

David Lamb, Aldershot, Avebury, 1995, 146 pages, $£ 30$.

I was talking to a colleague recently about the place of euthanasia in a course on medical ethics. He replied that death had been done to death, as indeed it had in most of the recent journals coming from North America. We wondered what more there was to write about death now. I confess that I was not, for this reason, looking forward to reviewing this book - but as I settled down to read it, I found that I was really enjoying myself and resisted all attempts to distract me until I had finished.

What gripped my attention early on was the first chapter, which addresses the question of whether philosophy is relevant to medical decision-making. Lamb centres his discussion around Anne Maclean's criticism of the claim that philosophers possess special expertise when addressing moral problems in medical ethics and takes a critical look at three ways in which moral philosophy has been brought to bear on medical problems: philosophy as a means of clarification, diversionary ethics and engineering ethics. He concludes by asserting that whilst philosophers should not claim moral authority this does not mean that they have nothing of value to contribute for they can offer " . . . an ability to reason well, avoid errors in argument and recognise them in the arguments of others" (page 11). But this is only useful when philosophers also make a very real attempt to get to grips with the subject matter. "Thus, much of applied philosophy - perhaps the most interesting part - lies, not in the search for an application of the best theory, 